\title{
Discrepancy in the perception of symptoms of cognitive decline between older adults and their family members: results of the Toyama dementia survey
}

\author{
Nobue Nakahori ${ }^{1,2^{*}}$ (D, Michikazu Sekine ${ }^{2}$, Masaaki Yamada ${ }^{2}$, Takashi Tatsuse ${ }^{2}$, Hideki Kido ${ }^{3}$ and Michio Suzuki ${ }^{4}$
}

\begin{abstract}
Background: Early consultation is important to delay the onset of dementia. The present study aimed to explore the reasons for delaying a consultation of dementia while focusing on the differences in the perception of cognitive decline between older adults and their family members.

Methods: A group of 663 older adults aged $\geq 65$ years and living with family members in Toyama Prefecture was surveyed. The questionnaires included items that measured changes in cognitive function noticed by older adults and their family members, and the Revised Hasegawa Dementia Scale (HDS-R). The degrees of consistency on the perception of mental changes that accompanied cognitive decline were measured using the Kappa statistic.

Results: Both older adults and their family members were well aware of "forgetfulness" as a symptom of cognitive decline. Only the perception of "loss of appetite" at the late stage of cognitive decline was consistent between older adults and their family $(\mathrm{k}=0.707)$. When older adults often noticed their own forgetfulness, their mean HDS-R score was 22.7, whereas that of the family members was 14.7. The combinations of perception of forgetfulness by older adults and their family members, and the mean HDS-R scores were unaware/unaware (mean HDS-R score = 27.0), aware/unaware (mean HDS-R score $=24.9$ ), aware/aware (mean HDS-R score $=15.5$ ), and unaware/aware (mean HDS-R score $=13.0$ ).

Conclusions: There were discrepancies in the perception of cognitive decline between older adults and their family members. Cognitive decline had progressed by the time that family members had noticed the symptom of forgetfulness in their older adult relatives. The perception gap regarding cognitive decline deters consultation of dementia.
\end{abstract}

Keywords: Cognitive decline, Family, Older adults, Perception, Subjective memory complaints

\section{Background}

Japan's population is aging with an unprecedented speed compared with other world regions. The incidence of dementia is estimated at approximately one in seven Japanese $\geq 65$ years of age, and the prevalence is projected to increase to approximately one in five by the year 2025 [1]. As there is no effective treatment for dementia at present, delaying

\footnotetext{
* Correspondence: n-nakahori@tsuruga-nu.ac.jp

${ }^{1}$ Faculty of Nursing Science, Tsuruga Nursing University, 78-2-1 Kizaki, Tsuruga, Fukui 914-0814, Japan

${ }^{2}$ Department of Epidemiology and Health Policy, Graduate School of Medicine and Pharmaceutical Sciences, University of Toyama, 2630 Sugitani, Toyama, Toyama 930-0194, Japan

Full list of author information is available at the end of the article
}

the onset of dementia is imperative. The Lancet Committee reported that interventions to delay the onset of dementia by one year may reduce the diagnosis of dementia worldwide by nine million by the year 2050 [2]. People with mild cognitive impairment have more possibilities to revert in comparison to those with advanced cognitive impairment [3]. This encourages both the family and older adults to receive appropriate treatment at an early stage and taking appropriate measures to prepare for symptom progression.

Early consultation is necessary to prevent and delay the onset of dementia. However, cognitive decline often progresses in older adults after consultation with a doctor about dementia [4]. Self-awareness decreases with the

(C) The Author(s). 2019 Open Access This article is distributed under the terms of the Creative Commons Attribution 4.0 International License (http://creativecommons.org/licenses/by/4.0/), which permits unrestricted use, distribution, and 
progression of cognitive decline, which is accompanied with a lower likelihood that older adults will seek medical consultation of dementia and long-term care services, even when encouraged [5]. The effect of treatment at the late stages of cognitive decline is limited [6, 7]. It is difficult for many families to accompany their elderly relatives with suspected dementia to consultation [8].

We examined the perception of cognitive decline by older adults themselves and their cohabitating family members to explore the reasons for the delay in consultation of dementia. Some studies have analyzed the symptoms of cognitive decline in older adults $[9,10]$, whereas few have investigated differences in the perception of cognitive decline between older adults and their family members who live together.

The present study aimed to explore the reasons for the delay in consultation of dementia, especially differences in perceptions at each stage of cognitive decline between older adults and their family members, as clarifying the reasons for the delay in consultation of dementia may contribute to delaying the onset of dementia.

\section{Methods}

\section{Participants}

A $0.5 \%$ random sample of the 307,582 residents of Toyama Prefecture who were $\geq 65$ years of age on October 1, 2013, was identified using computers to search a basic resident register. Of 1537 elderly individuals living at home or in elderly care facilities, 1303 (84.8\%) agreed to participate in this study. Public health nurses interviewed older adults and their family members, including husbands, wives, sons, daughters, children's spouses, and grandchildren. The person who was most familiar with the older adult among the family members responded to the questionnaire. The staff of the institution housing the older adults was also interviewed. The interviews were completed between June and August 2014 at the place of residence. Of the 1153 people who responded to all of the questions, 415 who were living unaccompanied, 30 who were institutionalized, and 45 who were separated from their family members were excluded from analysis. The remaining 663 older adults and their family members were included in the study. The characteristics of the participants are shown in Table 1.

Older adults and their family members received written explanations of the study aims and gave written informed consent to participate. The study protocol was approved by the Ethics Committee of the University of Toyama (Toyama, Japan) and was performed in accordance with the tenets of the Declaration of Helsinki.

\section{Revised Hasegawa dementia scale (HDS-R)}

The HDS-R is a nine-item questionnaire with a maximum score of 30 points [11] and is widely utilized for the screening of dementia in Japan. The HDS-R is strongly
Table 1 Characteristics of the 663 older adults

\begin{tabular}{|c|c|c|}
\hline & $n$ & $\%$ \\
\hline \multicolumn{3}{|l|}{ Sex } \\
\hline Men & 329 & 49.6 \\
\hline Women & 334 & 50.4 \\
\hline \multicolumn{3}{|l|}{ Age (years) } \\
\hline Mean age & $76.0 \pm 7.59$ & \\
\hline $65-74$ & 317 & 47.8 \\
\hline $75-84$ & 247 & 37.3 \\
\hline$\geq 85$ & 99 & 14.9 \\
\hline \multicolumn{3}{|l|}{ Family } \\
\hline Husband & 177 & 26.7 \\
\hline Wife & 294 & 44.3 \\
\hline Son & 66 & 10.0 \\
\hline Daughter & 56 & 8.4 \\
\hline Child's spouse & 62 & 9.4 \\
\hline Grandchild & 8 & 1.2 \\
\hline \multicolumn{3}{|l|}{ Living partner } \\
\hline Spouse & 215 & 32.4 \\
\hline Parents & 19 & 2.9 \\
\hline Children couple & 63 & 9.5 \\
\hline Children couple and grandchildren & 174 & 26.2 \\
\hline Children couple and grandchildren couple & 11 & 1.7 \\
\hline Children (unmarried) & 125 & 18.9 \\
\hline Grandchildren couple & 1 & 0.2 \\
\hline Others & 55 & 8.3 \\
\hline \multicolumn{3}{|l|}{ Hasegawa Dementia Scale Score (points) } \\
\hline Mean score & $25.8 \pm 5.80$ & \\
\hline$\leq 20$ & 80 & 12.1 \\
\hline $21-24$ & 78 & 11.8 \\
\hline$\geq 25$ & 505 & 76.2 \\
\hline
\end{tabular}

correlated with the Mini-Mental State Examination [12]. Its validity has been confirmed with a sensitivity and specificity of 0.90 and 0.82 , respectively, when the cut-off point is set to 20/21 [11]. Dementia is suspected when the HDS- $\mathrm{R}$ score is $\leq 20$. The average HDS-R score for healthy subjects diagnosed as not having dementia is 24.27 [11]. According to the cut-off and mean scores of the HDS-R, the subjects were assigned to one of three groups: greater than the mean ( $\geq 25$ points), less than the mean (21-24 points), and suspected dementia ( $\leq 20$ points).

\section{Mental changes noticed by older adults}

Older adults were questioned about changes in 14 mental state symptoms in the previous 3 months. Items of each mental change were answered with either "YES" or "NO." The symptoms are listed in Table 2 [13-16]. The 
Table 2 Mental changes noticed by the 663 older adults

\begin{tabular}{|c|c|c|c|c|c|c|}
\hline \multirow[t]{3}{*}{ Hasegawa Dementia Scale Score } & \multirow{2}{*}{$\begin{array}{l}\leq 20(a) \\
(n=80)\end{array}$} & \multirow{2}{*}{$\begin{array}{l}21-24(b) \\
(n=78)\end{array}$} & \multirow{2}{*}{$\begin{array}{l}\geq 25(c) \\
(n=505)\end{array}$} & \multirow[t]{2}{*}{ Chi-square Test } & \multicolumn{2}{|c|}{ Adjusted Residual } \\
\hline & & & & & & \\
\hline & $\%$ & $\%$ & $\%$ & $P$ value & $\mathrm{O}<\mathrm{E}$ & $E<O$ \\
\hline Loss of appetite & 6.3 & 5.1 & 4.2 & 0.679 & & \\
\hline Being unable to sleep at night & 11.3 & 9.0 & 11.3 & 0.829 & & \\
\hline Feeling more moody in the mornings and less so in the evenings & 2.5 & 1.3 & 3.2 & 0.635 & & \\
\hline Losing motivation and interest in things & 17.5 & 10.3 & 6.9 & 0.006 & c & a \\
\hline Worrying about their health & 16.3 & 9.0 & 6.3 & 0.008 & c & a \\
\hline Frequently feeling anxious & 8.8 & 9.0 & 5.0 & 0.189 & & \\
\hline Feeling restless & 2.5 & 1.3 & 1.8 & 0.844 & & \\
\hline $\begin{array}{l}\text { Feeling compelled to do things despite not believing there is a } \\
\text { need for them (washing hands, closing doors, checking the state } \\
\text { of open flames, among others) }\end{array}$ & 5.0 & 3.8 & 3.2 & 0.694 & & \\
\hline Fluctuating mood & 8.8 & 5.1 & 2.4 & 0.011 & c & a \\
\hline Sometimes wanting to die & 5.0 & 2.6 & 2.6 & 0.475 & & \\
\hline Becoming more forgetful & 46.3 & 33.3 & 14.9 & $<0.001$ & c & $a, b$ \\
\hline
\end{tabular}

$\mathrm{O}<\mathrm{E}$, the rate of the measured value is significantly lower than the rate of the expected value; $\mathrm{E}<\mathrm{O}$, the rate of the expected value is significantly higher than the rate of the measured value

questionnaires were completed by the family members by asking older adults about their awareness of changes.

\section{Mental changes in older adults noticed by family}

Family members answered questions about changes in 19 symptoms of the mental state of their older adult relatives during the previous 3 months. Items of each mental change were answered with either "YES" or "NO." The symptoms have been previously described and are shown in Table 3 [13-16].

\section{Statistical analysis}

All statistical analyses were performed using IBM SPSS Statistics for Windows, version 23 (IBM Corp., Armonk, NY, USA). The characteristics of older adults, such as sex, age, cohabitating family members, household composition, and HDS-R scores were reported using descriptive statistics by calculating the number and percentage of each variable. Mental changes recognized at each stage of cognitive decline were reported by calculating the percentage of positive changes. HDS- $\mathrm{R}$ scores of $\leq 20,21-24$, and $\geq 25$ points were compared using the chi-square test to investigate the transition of symptoms at each stage of cognitive decline. In addition, residual analysis was performed to differentiate the stages that are significantly frequent from those that are significantly less frequent. Both family members and older adults were questioned regarding six common symptoms of cognitive decline in older adults. For these symptoms, the degree of agreement of recognition was evaluated using the Kappa statistic. The mean HDS-R scores of older adults who noticed their forgetfulness and the mean values of their family members who noticed forgetfulness of their older adult relatives were compared. The level of statistical significance was set at 5\%.

\section{Results}

The characteristics of the 663 older adults [329 (49.6\%) men and 334 (50.4\%) women] are presented in Table 1. The mean age of the older adults was $76.0 \pm 7.59$ years. The family members included 117 husbands (26.7\%), 294 wives (44.3\%), 66 sons (10.0\%), 56 daughters (8.4\%), 62 children's spouses (9.4\%), and eight grandchildren (1.2\%). Living partners included 215 spouses (32.4\%), 19 parents (2.9\%), 63 children couple (9.5\%), 174 children couple and grandchildren (26.2\%), 11 children couple and grandchildren couple (1.7\%), and 125 children (unmarried) (18.9\%), one grandchildren couple $(0.2 \%)$, and 55 others $(8.3 \%)$. The HDS-R score was $\leq 20$ points in 80 (12.1\%) participants, $21-24$ points in $78(11.8 \%)$, and $\geq$ 25 points in 505 (76.2\%).

Table 2 shows the percentages of older adults who noticed mental changes ordered by the level of cognitive decline. The mental changes accompanying each stage of cognitive decline that were noticed by the older adults themselves are presented in decreasing order. The most common changes in cognitive decline were "becoming more forgetful (14.9\%)" and "being unable to sleep at night (11.3\%)" in the HDS-R $\geq 25$ group, "becoming more forgetful (33.3\%)" and "losing motivation and interest in things (10.9\%)" in the HDS- $\mathrm{R}=21-24$ group, and "becoming more forgetful (46.3\%)" and "losing motivation and interest in things (17.5\%)" in the HDS-R $\leq$ 20 group. Four of the 11 symptoms were significantly associated with the HDS-R score. Subgroup analysis revealed that these items were significantly more common 
Table 3 Mental changes in the 663 older adults that were noticed by their family members

\begin{tabular}{|c|c|c|c|c|c|c|}
\hline \multirow[t]{3}{*}{ Hasegawa Dementia Scale score } & \multirow{3}{*}{$\begin{array}{l}\leq 20(\mathrm{a}) \\
(n=80) \\
\%\end{array}$} & \multirow{3}{*}{$\begin{array}{l}21-24(b) \\
(n=78) \\
\%\end{array}$} & \multirow{3}{*}{$\begin{array}{l}\geq 25(c) \\
(n=505) \\
\%\end{array}$} & \multirow{3}{*}{$\begin{array}{l}\text { Chi-square } \\
\text { test } \\
P \text { value }\end{array}$} & \multirow{2}{*}{\multicolumn{2}{|c|}{$\begin{array}{l}\text { Adjusted } \\
\text { residual }\end{array}$}} \\
\hline & & & & & & \\
\hline & & & & & $\mathrm{O}<\mathrm{E}$ & $E<O$ \\
\hline Lacking vitality and feeling depressed & 10.0 & 5.1 & 2.0 & $<0.001$ & c & a \\
\hline Loss of appetite & 7.5 & 6.4 & 3.0 & 0.074 & c & \\
\hline Constantly experiencing negative thoughts & 11.3 & 9.0 & 4.6 & 0.028 & c & a \\
\hline Feeling restless & 11.3 & 3.8 & 1.6 & $<0.001$ & c & a \\
\hline Feeling more moody in the mornings and less so in the evenings & 3.8 & 0.0 & 3.2 & 0.260 & & \\
\hline Worrying about their health & 5.0 & 1.3 & 3.1 & 0.411 & & \\
\hline $\begin{array}{l}\text { Frequently consulting physicians and successively changing medical } \\
\text { institutions }\end{array}$ & 0.0 & 0.0 & 1.2 & 0.388 & & \\
\hline Being unable to sleep at night & 8.8 & 7.7 & 5.3 & 0.398 & & \\
\hline $\begin{array}{l}\text { Assuming the intentions of strangers to be bad and being convinced } \\
\text { that things that are not fact are true }\end{array}$ & 6.3 & 5.1 & 1.0 & 0.001 & c & a \\
\hline Seeing things that are not there and hearing voices & 10.0 & 2.6 & 0.4 & $<0.001$ & c & a \\
\hline Becoming more forgetful & 38.8 & 14.1 & 1.0 & $<0.001$ & c & $a, b$ \\
\hline Being half awake at night making noise and moving about & 5.0 & 1.3 & 0.2 & 0.001 & c & a \\
\hline Sometimes confusing night and day & 17.5 & 5.1 & 0.8 & $<0.001$ & c & a \\
\hline Occasionally getting lost when going out & 2.5 & 0.0 & 0.0 & 0.001 & c & a \\
\hline Becoming very stubborn and obstinate & 21.3 & 10.3 & 5.0 & $<0.001$ & c & a \\
\hline Diminished consideration for others (selfishness) & 25.0 & 7.7 & 2.6 & $<0.001$ & c & a \\
\hline Emotional instability & 17.5 & 5.1 & 2.2 & $<0.001$ & c & a \\
\hline Preferring to stay home and being unwilling to meet other people & 12.5 & 7.7 & 1.8 & $<0.001$ & c & a \\
\hline Losing motivation and interest in things & 25.0 & 5.1 & 2.2 & $<0.001$ & c & a \\
\hline
\end{tabular}

$\mathrm{O}<\mathrm{E}$, the rate of the measured value is significantly lower than the rate of the expected value; $\mathrm{E}<\mathrm{O}$, the rate of the expected value is significantly higher than the rate of the measured value

in participants with HDS- $\mathrm{R}$ scores $\leq 20$ points and significantly less common in those with scores $\geq 25$ points. "Forgetfulness" was also significantly more common in participants with HDS-R scores of 21-24 points.

Table 3 shows the percentage of family members who noticed mental changes in their older adult relatives, as ordered by the level of cognitive decline. The mental changes accompanying cognitive decline that family members noticed at each stage in decreasing order were "being unable to sleep at night (5.3\%)" and "becoming very stubborn and obstinate (5.0\%)" in the HDS-R $\geq 25$ group, "becoming more forgetful (14.1\%)" and "becoming very stubborn and obstinate (10.3\%)" in the HDS-R = 21-24 group, and "becoming more forgetful (38.8\%)," "losing motivation and interest in things (25.0\%)," and "diminished consideration for others (selfishness) (25.0\%)" in the HDS-R $\leq 20$ group. Of the 19 symptoms, 14 were significantly associated with the HDS-R score. Subgroup analysis revealed that these items were significantly more common in participants with HDS-R scores of $\leq 20$ points and significantly less common in those with scores of $\geq 25$ points. "Forgetfulness" was also significantly more common in participants with HDS-R scores of 21-24 points.
Table 4 shows the percentage of each of the four combinations of mental changes with or without older adults' awareness and with or without their family's awareness in each group divided into three subgroups based on the HDS-R score. Table 4 also shows the coincidence in perception of cognitive decline-related mental changes noticed by family members and those noticed by the older adults themselves. The perception of loss of appetite in older adults with HDS-R scores $\leq 20$ points $(\kappa=0.707)$ was in substantial agreement with the perception of the cohabitating family members. There was poor agreement in the perception of symptoms, except for loss of appetite, in all three HDS-R groups between older adults and their family members.

Table 5 shows the average HDS-R scores of older adults who noticed forgetfulness and those of family members who noticed forgetfulness in their older adult relatives. Table 5 also shows the average HDS-R scores for four combinations of older adults who do and do not notice their forgetfulness and their family members who do and do not notice the forgetfulness of older adults. The mean HDS-R scores of older adults and family members who noticed "becoming more forgetful" were 
Table 4 Degree of coincidence of mental changes associated with cognitive decline noticed by the 663 older adults and their family members

\begin{tabular}{|c|c|c|c|c|c|c|c|c|c|c|c|}
\hline \multicolumn{3}{|c|}{ Hasegawa Dementia Scale Score } & \multirow{2}{*}{\multicolumn{3}{|c|}{$\begin{array}{l}\leq 20 \text { points }(n=80) \\
\text { Family }\end{array}$}} & \multirow{2}{*}{\multicolumn{3}{|c|}{$\frac{21-24 \text { points }(n=78)}{\text { Family }}$}} & \multirow{2}{*}{\multicolumn{3}{|c|}{$\begin{array}{l}\geq 25 \text { points }(n=505) \\
\text { Family }\end{array}$}} \\
\hline & & & & & & & & & & & \\
\hline & & & Yes \% & No $\%$ & $\overline{\mathrm{k} \text { statistic }}$ & Yes \% & No $\%$ & $\overline{\mathrm{K} \text { statistic }}$ & Yes \% & No $\%$ & $\overline{\mathrm{K} \text { statistic }}$ \\
\hline Loss of appetite & Participants & Yes & 5.0 & 1.3 & 0.707 & 3.8 & 1.3 & 0.647 & 2.0 & 2.2 & 0.540 \\
\hline & & No & 2.5 & 91.3 & & 2.6 & 92.3 & & 1.0 & 94.9 & \\
\hline Being unable to sleep & Participants & Yes & 3.8 & 7.5 & 0.307 & 3.8 & 5.1 & 0.413 & 3.8 & 7.5 & 0.410 \\
\hline & & No & 5.0 & 83.8 & & 3.8 & 87.2 & & 1.6 & 87.1 & \\
\hline Losing motivation and & Participants & Yes & 7.5 & 10.0 & 0.185 & 2.6 & 7.7 & 0.284 & 0.8 & 6.1 & 0.146 \\
\hline interest in things & & No & 17.5 & 65.0 & & 2.6 & 87.2 & & 1.4 & 91.7 & \\
\hline Worrying about their & Participants & Yes & 3.8 & 12.5 & 0.299 & 0.0 & 9.0 & -0.023 & 1.6 & 4.8 & 0.304 \\
\hline & & No & 1.3 & 82.5 & & 1.3 & 89.7 & & 1.6 & 92.1 & \\
\hline Feeling restless & Participants & Yes & 1.3 & 1.3 & 0.147 & 1.3 & 0.0 & 0.306 & 0.4 & 1.4 & 0.222 \\
\hline & & No & 10.0 & 87.5 & & 2.6 & 96.2 & & 1.2 & 97.0 & \\
\hline Becoming more & Participants & Yes & 26.3 & 20.0 & 0.339 & 11.5 & 21.8 & 0.360 & 0.6 & 14.3 & 0.058 \\
\hline & & No & 12.5 & 41.3 & & 2.6 & 64.1 & & 0.4 & 84.8 & \\
\hline
\end{tabular}

$22.7 \pm 8.00$ and $14.7 \pm 8.30$, respectively. The combinations of perception of forgetfulness by older adults and their family members, and the mean HDS-R scores $( \pm$ standard deviation, SD) were unaware/unaware (27.0 \pm $3.98)$, aware/unaware $(24.9 \pm 6.53)$, aware/aware (15.5 \pm $8.05)$, and unaware/aware $(13.0 \pm 8.94)$.

\section{Discussion}

In Japan, families find it difficult getting older adults suspected of having dementia to a medical consultation. Early intervention for dementia is an effective means of delaying its onset. In reality, there are few older adults who get early consultations or interventions. The present study assessed the reasons for delaying the consultation for dementia focusing on the differences in the perception of cognitive decline between older adults and their family members. The result showed that family members do not know when older adults begin to notice forgetfulness and it is unlikely that older adults see a doctor at this time. Moreover, by the time the family notices the older adult' forgetfulness, the older adult's cognitive decline is significant. The results of this study suggest that the ideal time for early intervention is when older adults become aware of their forgetfulness.

Older adults report that they notice mental changes at the early stage of cognitive decline [17-21]. As in previous studies, our results showed that older adults were more aware of forgetfulness than their family members at the early stage of cognitive decline. When the stage of cognitive decline progresses, older adults are likely to experience low motivation, be concerned about health, and have fluctuating mood. The family is aware of the low motivation but unaware of the concern about health. These changes are considered to be an indicator that should be noted as mental changes noticed by the older adults with cognitive decline. The symptom most recognized by older adults in any stage of cognitive decline was forgetfulness. The results of the present study indicated that self-awareness of forgetfulness is a sensitive indicator of cognitive decline, as subjective memory complaints were strongly correlated with the HDS-R score. Previous studies have reported that older people with subjective memory complaints are at a greater risk of future cognitive impairment [22-25].

Table 5 Mean HDS-R scores of older adults and their family members who notice forgetfulness.

\begin{tabular}{|c|c|c|c|c|c|}
\hline & & \multirow[b]{4}{*}{ Perception of forgetfulness } & & & \multirow{4}{*}{$\begin{array}{l}n=663 \\
\text { Older adults notice their forgetfulness }\end{array}$} \\
\hline & & & \multicolumn{2}{|l|}{ Family } & \\
\hline & & & \multicolumn{2}{|c|}{ HDS-R scores, mean \pm SD } & \\
\hline & & & Yes & No & \\
\hline \multirow[t]{3}{*}{ Older adults } & \multirow[t]{3}{*}{ HDS-R scores, mean \pm SD } & Yes & $15.5 \pm 8.05$ & $24.9 \pm 6.53$ & \multirow[t]{3}{*}{$22.7 \pm 8.00$} \\
\hline & & No & $13.0 \pm 8.94$ & $27.0 \pm 3.98$ & \\
\hline & & $\begin{array}{l}\text { Family members notice the } \\
\text { forgetfulness of older adults }\end{array}$ & \multicolumn{2}{|l|}{$14.7 \pm 8.30$} & \\
\hline
\end{tabular}


As in previous studies [26, 27], our results showed that the family members of older adults in this study were aware of mental changes that occurred with each stage of cognitive decline. With the progression of cognitive decline, family members were likely to notice lower motivation, selfishness, and stubbornness of their older adult relatives. The symptom that the family members most perceived in any stage of cognitive decline was forgetfulness. However, the mean HDS-R scores of older adults who notice their own forgetfulness were greater by about eight points than that of the family members. In other words, by the time family members noticed the symptoms of forgetfulness in their older adult relatives, the stage of dementia had considerably progressed. In many cases, children of older adults may notice something unusual about their parents, but they have difficulty in recognizing such changes as cognitive decline [28]. The present study showed that it is difficult for family members to notice mental changes in older adults even if they are cohabitating.

Among older adults and their family members, the perceptions of most of symptoms of cognitive decline were discrepant. Only the perception of loss of appetite was consistent between older adults and their family members at a HDS- $\mathrm{R}$ score of $\leq 20$ points. This is probably due to the family members being able to directly observe changes in daily dietary habits. However, the perceptions of symptoms were not consistent between older adults and their family members at a HDS-R score of $\geq 21$ points. The degree of coincidence of perception of forgetfulness between older adults and family members was low. We found that family members tended not to notice forgetfulness even when older adults with normal cognitive function sensed forgetfulness, unless older adults said it. Conversely, we speculate that older adults with low cognitive function gradually lose their ability to perceive their own forgetfulness; thus, their perception begins to diverge from that of their family members, which suggests that it would be too late once their family members had noticed cognitive decline of their older adult relatives.

We depicted the four combinations of perception of forgetfulness (Fig. 1) between older adults and family members as unaware/unaware (phase 1), aware/unaware (phase 2), aware/aware (phase 3), and unaware/aware (phase 4). The average HDS-R scores for the four combinations of perception of forgetfulness of older adults/ family members were in descending order. In particular, in the first phase (mean HDS-R score $=27.0$ ), both older adults and family members are unaware of the symptom of forgetfulness, as cognitive function seems to be normal. In the second phase (mean HDS-R score $=24.9$ ), older adults are aware of forgetfulness, whereas their family members are not. Treatment should be effective

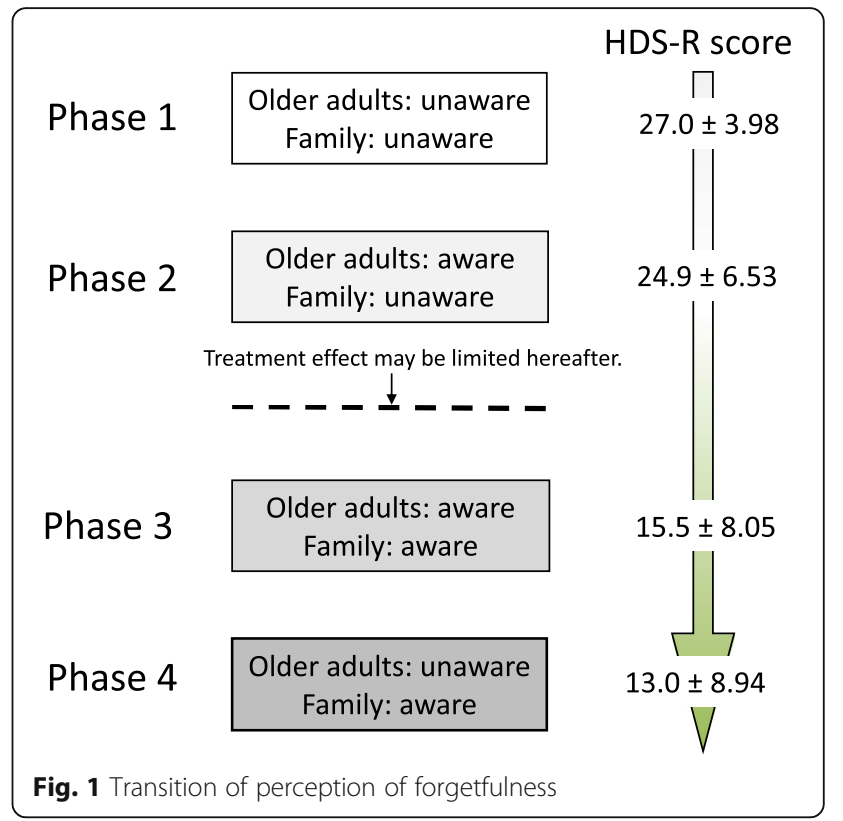

in this phase. In the third phase (mean HDS-R score = 15.5), both older adults and their family members are aware of the symptom of forgetfulness and many start to consider a consultation of dementia, but the effect of treatment may be limited. In the fourth phase (mean HDS-R score $=13.0$ ), older adults are unaware of forgetfulness, but family are aware. As cognitive decline of older adults is progressed in this phase, and the family members may have difficulty in taking their older adult relatives to consultation of dementia. Although not everyone goes through these phases in the order shown, any preventive measures should be important, especially in the second phase.

The results of the present study indicate the importance of subjective memory complaints of older adults. Reportedly, the family members living with older adults tend to disrupt the consultation [29]. Older adults who notice their forgetfulness are less likely to consult a doctor if some of their family members regard cognitive decline as mild loss of the ability to remember facts as observed in a normal part of the aging process. Children tend to deny that their parents have dementia $[28,30]$. Normalcy bias may effectively lead to the dismissal of dementia by both older adults and their family members. The present study suggested that early measures for delaying the onset of dementia would be required when older adults themselves notice their forgetfulness.

There were some limitations to this study that should be addressed. First, there are limitations to the survey conducted by families using the questionnaire. We did not closely evaluate the participation of older adults and their family members in shared daily activities. In addition, this questionnaire was not validated for reliability. This questionnaire does not 
cover all the mental changes associated with cognitive decline; therefore, the results need to be interpreted based on this limitation. However, it includes symptoms that are considered to be clinically important [13-16]. As the family questioned older adults about their awareness of changes, they may have influenced the perception results of the older adults. However, in this survey, the family members were instructed to read out each question to the elderly and fill in the responses exactly as they were answered; therefore, it is unlikely that the family has changed their answers. A study reported that the proxy quality of life assessment of patients with dementia tends to be lower than self-assessment [31]. This must be considered because the self-assessment in the questionnaire was completed by family members in the present study. Second, this is a cross-sectional study and does not longitudinally investigate the change in the perception of cognitive decline among older adults and their family members. However, this study showed a possibility that there are stages in the combinations of the perception of forgetfulness, which may help physicians to diagnose an early stage of dementia; thus, the results of this study may be useful in primary care settings.

\section{Conclusions}

The results of this study showed discrepancies in the perception of most symptoms of cognitive decline between older adults and their family members. Both older adults and their family members significantly noticed forgetfulness. However, the mean HDS-R scores of older adults who noticed their own forgetfulness were greater by about eight points than those of family members. Cognitive decline progresses by the time that family members take notice of the symptom of forgetfulness of their older adult relatives. It is suggested that the perception gap shown above between older adults and their family members regarding cognitive decline works to deter consultation of dementia. Subjective memory complaints are sensitive indicators of cognitive decline. These results suggest that early measures to delay the onset of dementia are required once older adults start having concerns about forgetfulness.

\section{Abbreviations}

Cl: Confidence interval; OR: Odds ratio; HDS-R: Revised Hasegawa Dementia Scale

\section{Acknowledgements}

The authors would like to express their deep appreciation for the cooperation of the Toyama Prefectural Health and Welfare Bureau, Toyama Neuropsychiatrists Association, the contributing members of the Toyama municipalities, and all survey participants.

\section{Authors' contributions}

NN, MS1, MY, TT, HK, and MS2 contributed to the study design, data acquisition, analysis, and interpretation, and manuscript preparation. All authors read and approved the final version of the manuscript.

\section{Funding}

No funding was received for this study.

\section{Availability of data and materials}

The datasets analyzed during the current study are available from the corresponding author upon reasonable request.

\section{Ethics approval and consent to participate}

The study protocol was approved by the Ethics Committee of the University of Toyama. Consent to participate in the study was provided in a written format. For participants with cognitive impairment, consent was provided by their family members or proxies.

\section{Consent for publication}

Not applicable.

\section{Competing interests}

The authors have no competing interests to declare.

\section{Author details}

${ }^{1}$ Faculty of Nursing Science, Tsuruga Nursing University, 78-2-1 Kizaki, Tsuruga, Fukui 914-0814, Japan. ${ }^{2}$ Department of Epidemiology and Health Policy, Graduate School of Medicine and Pharmaceutical Sciences, University of Toyama, 2630 Sugitani, Toyama, Toyama 930-0194, Japan. ${ }^{3}$ Kiseikai, Kido Clinic, 244 Honoki, Imizu, Toyama 934-0053, Japan. ${ }^{4}$ Department of Neuropsychiatry, Graduate School of Medicine and Pharmaceutical Sciences, University of Toyama, 2630 Sugitani, Toyama, Toyama 930-0194, Japan.

Received: 13 April 2019 Accepted: 19 December 2019

Published online: 26 December 2019

\section{References}

1. Ministry of Health, Labour and Welfare. A comprehensive strategy for the promotion of dementia measures (a new orange plan). https://www.mhlw. go.jp/stf/seisakunitsuite/bunya/0000064084.html. Accessed 17 Jan 2019.

2. Livingston G, Sommerlad A, Orgeta V, Costafreda SG, Huntley J, Ames D, et al. Dementia, prevention, intervention, and care. Lancet. 2017;390: 2673-734.

3. Brodaty H, Heffernan M, Kochan NA, Draper B, Trollor JN, Reppermund S, et al. Mild cognitive impairment in a community sample: the Sydney memory and ageing study. Alzheimers Dement. 2013;9:310-7.

4. Miyoshi K, Ohyagi Y, Yamasaki T, Himeno E, Sakurai O, Sasaki K, et al. Memory clinic operated by the departments of neurology and psychiatry Kyushu University Hospital: retrospective survey of a six-year experience. Neuro Therapeut. 2008;25:597-603 https://jglobal.jst.go.jp/en/detail? JGLOBAL_ID=200902209915845329\&e=reference\%2Farticle.

5. Ito K, Inagaki H, Sugiyama M, Awata S. What makes a person a complex case?: a field survey of older people with undiagnosed dementia. Jpn J Geriatr Psychiatr. 2015:26:55-66.

6. Hamuro A, Saito S. Five Alzheimer's disease cases with refractory behavioral psychological symptoms of dementia treated with blonanserin. Psychogeriatr. 2010;10:198-200.

7. Ogino A, Sugiyama T, Yamaguchi N. Efficacy of donepezil for memory and cognition dysfunction associated with Alzheimer-type dementia and factors related to its efficacy. Clin Neuropsychopharmacol Therapeut. 2007;10:93-9.

8. Shinagawa J, Imamura T, Yatabe Y, Hashimoto M, Nakayama K, Ikeda M. Comparative study of family care infrastructure for dementia in 3 regions -focusing on living-in person and accompanying person at first visit of patient visiting specialized outpatient clinics. Clin Psychiatr 2012;54:501-507. https://doi.org/https://doi.org/10.11477/mf.1405102176

9. Jessen F, Amariglio RE, Boxtel MV, Breteler M, Ceccaldi M, Chételat G, et al. A conceptual framework for research on subjective cognitive decline in preclinical Alzheimer's disease. Alzheimers Dement. 2014;10:844-52.

10. Jessen F, Wiese B, Cvetanovska G, Kaduszkiewicz H, Kölsch H, Luck T, et al. Patterns of subjective memory impairment in the elderly: association with memory performance. Psychol Med. 2007;37:1753-62.

11. Kato S, Shimogaki H, Onodera A, Ueda H, Oikawa K, Ikeda K. Development of the revised version of Hasegawa's dementia scale (HDS-R). Jpn J Geriatr Psychiatr. 1991;2:1339-47.

12. Folstein MF, Folstein SE, McHugh PR. "Mini-mental state"; a practical method for grading the cognitive state for the clinician. J Psychiat Res. 1975;12:189-98. 
13. World Health Organization and Alzheimer's Disease International. Dementia: a public health priority. https://www.who.int/mental_health/publications/ dementia_report_2012/en/ Accessed 17 Jan 2019.

14. Ministry of Health, Labour and Welfare. Dementia prevention/ support manual (revised edition). https:/www.mhlw.go.jp/topics/2009/05/dl/tp05 01-1h_0001.pdf. Accessed 17 Jan 2019.

15. Japanese Society of Neurology. Treatment guidelines for dementing disorders 2017. https://www.neurology-jp.org/guidelinem/nintisyo_2017. html. Accessed 17 Jan 2019.

16. Lyketsos CG, Lopez O, Jones B, Fitzpatrick AL, Breitner J, DeKosky S. Prevalence of neuropsychiatric symptoms in dementia and mild cognitive impairment: results from the cardiovascular health study. JAMA. 2002;288:1475-83.

17. Harada M, Nishida M, Yamada Y, Kokuryu A, Sugihara Y, Takechi H. Anxieties and self in early-stage Alzheimer's disease. J Jpn Soc Dement Care. 2009:8:40-50.

18. Balsis S, Carpenter BD, Storandt M. Personailty change precedes clinical diagnosis of dementia of the Alzheimer type. Psychol Sci. 2005;60:98-101.

19. Rueda A, Lau K, Saito N, Harvey D, Risacher SL, Aisen PS, et al. Self-rated and informant-rated everyday function in comparison to objective markers of Alzheimer's disease. Alzheimers Dement. 2015;11:1080-9.

20. Rankin KP, Baldwin E, Pace-Savitsky C, Kramer JH, Miller BL. Self awareness and personality change in dementia. J Neurol Neurosurg Psychiatry. 2005; 76:632-9.

21. Piras F, Piras F, Orfei MD, Caltagirone C, Spalletta G. Self-awareness in mild cognitive impairment: quantitative evidence from systematic review and meta-analysis. Neurosci Biobehav Rev. 2016;61:90-107.

22. Mitchell AJ, Beaumont H, Ferguson D, Yadegarfar M, Stubbs B. Risk of dementia and mild cognitive impairment in older people with subjective memory complaints: meta- analysis. Acta Psychiatr Scand. 2014:1-13.

23. Kryscio RJ, Abner EL, Cooper GE, Fardo DW, Jicha GA, Nelson PT, et al. Selfreported memory complaints implications from a longitudinal cohort with autopsies. Neurol. 2014:83:1-7.

24. Luck T, Riedel-Heller SG, Luppa M, Wiese B, Wollny A, Wagner M, et al. Risk factors for incident mild cognitive impairment-results from the German study on ageing, cognition and dementia in primary care patients (AgeCoDe). Acta Psychiatr Scand. 2010;121:260-72.

25. Hohman TJ, Beason-Held L, Lamar M, Resnick SM. Subjective cognitive complaints and longitudinal changes in memory and brain function. Neuropsychology. 2011;25:125-30.

26. Caselli RJ, Chen K, Locke DE, Lee W, Roontiva A, Bandy D, et al. Subjective cognitive decline: self and informant comparisons. Alzheimers Dement. 2014:10:93-8.

27. Fujiwara Y, Amano H, Takabayashi K, Kumagai S, Yoshida Y, Yoshida H, et al. Factors related discrepancy in evaluation on functional capacity between reports by community-dwelling older people with cognitive decline and their family members. Jpn J Geriat. 2003;40:487-96.

28. Tanimoto $Y$, Omachi $Y$. The process until the family of elderly with dementia visits the hospital. Coll J Jpn Nurs. 2006;36:15-7.

29. Amino K, Katayama S, limori M. Association between clinical and social characteristics and the severity of dementia in patients with Alzheimer's disease at the time of first presentation at a specialist clinic. JPN bull Soc Psychiat. 2011;20:8-16

30. Shikano Y, Hangmi K, Kimura T, Honma A. Why is early treatment for dementia difficult? Barrier factors from the viewpoint of families and necessity of providing information. J Jpn Soc Dement Care. 2003;2:158-81.

31. Robertson S, Cooper C, Hoe J, Hamilton O, Stringer A, Livingston G. Proxy rated quality of life of care home residents with dementia: a systematic review. Int Psychogeriatr. 2017;29:569-81.

\section{Publisher's Note}

Springer Nature remains neutral with regard to jurisdictional claims in published maps and institutional affiliations.

Ready to submit your research? Choose BMC and benefit from:

- fast, convenient online submission

- thorough peer review by experienced researchers in your field

- rapid publication on acceptance

- support for research data, including large and complex data types

- gold Open Access which fosters wider collaboration and increased citations

- maximum visibility for your research: over $100 \mathrm{M}$ website views per year

At $\mathrm{BMC}$, research is always in progress.

Learn more biomedcentral.com/submissions 